\title{
Argan oil improves surrogate markers of CVD in humans
}

\author{
Souad Sour ${ }^{1}$, Meriem Belarbi ${ }^{1}$, Darine Khaldi ${ }^{1}$, Nassima Benmansour ${ }^{1}$, Nassima Sari ${ }^{1}$, Abdelhafid Nani ${ }^{1}$, \\ Farid Chemat ${ }^{2}$ and Francesco Visioli ${ }^{3 *}$ \\ ${ }^{1}$ Natural Products Laboratory, Department of Biology, Faculty of Natural and Life Sciences and Sciences of Earth and \\ the Universe, Abu Bakr Belkaid University, Tlemcen, Algeria \\ ${ }^{2}$ Eco-Extraction Laboratory of Natural Products (GREEN), University of Avignon and Pays de Vaucluse, France \\ ${ }^{3}$ Laboratory of Functional Foods, IMDEA-Food, Calle Faraday 7, 28049 Madrid, Spain
}

(Submitted 5 May 2011 - Final revision received 6 July 2011 - Accepted 4 August 2011 - First published online 15 November 2011)

\begin{abstract}
Limited - though increasing - evidence suggests that argan oil might be endowed with potential healthful properties, mostly in the areas of CVD and prostate cancer. We sought to comprehensively determine the effects of argan oil supplementation on the plasma lipid profile and antioxidant status of a group of healthy Algerian subjects, compared with matched controls. A total of twenty healthy subjects consumed $15 \mathrm{~g} / \mathrm{d}$ of argan oil - with toasted bread - for breakfast, during 4 weeks (intervention group), whereas twenty matched controls followed their habitual diet, but did not consume argan oil. The study lasted $30 \mathrm{~d}$. At the end of the study, argan oil-supplemented subjects exhibited higher plasma vitamin E concentrations, lower total and LDL-cholesterol, lower TAG and improved plasma and cellular antioxidant profile, when compared with controls. In conclusion, we showed that Algerian argan oil is able to positively modulate some surrogate markers of CVD, through mechanisms which warrant further investigation.
\end{abstract}

\section{Key words: Argan oil: Argania spinosa: CVD: Atherosclerosis: Cholesterol: Lipid oxidation: Mediterranean diet}

Diet and its components play major roles in the onset and development of several degenerative diseases such as atherosclerosis, CVD, cancer and neurodegeneration ${ }^{(1)}$. In this respect, adherence to the Mediterranean diet is associated with lower incidence of CVD and cancer ${ }^{(2,3)}$. It must be emphasised that the term 'Mediterranean diet' encompasses several diverse dietary profiles typical of the Mediterranean basin $^{(4,5)}$. Indeed, some differences, e.g. with respect to alcohol consumption or protein intake, exist among the various Mediterranean countries ${ }^{(5)}$. Among the various components of the Mediterranean diet, much attention is being paid to olive oil, because its consumption is associated with favourable cardiovascular outcomes ${ }^{(6)}$. However, some countries, namely those in the Maghreb area, also use argan oil for culinary and cosmetic applications ${ }^{(7)}$. Indeed, accumulating evidence suggests that argan oil might be endowed with potential healthful properties, mostly in the areas of $\mathrm{CVD}^{(8)}$ and prostate cancer ${ }^{(9)}$. As an example, several recent studies reported hypolipidaemic, hypocholesterolaemic and antihypertensive effects of argan oil in the $\operatorname{rat}^{(7,10)}$. Argan oil is obtained from the fruit of Argania spinosa (Sapotaceae), an endemic tree which mostly grows in South-western Morocco. Argan trees also grow in Algeria, namely in the Tindouf countryside. While technological advancement, e.g. Soxlet's extraction, is changing argan oil production, most of its making still follows traditional procedures, i.e. hand-grounding and cold-pressing of the kernels, yielding yellowish, nutty-flavoured products ${ }^{(7)}$. The fatty acid profile of argan oil consists of approximately 45\% MUFA, approximately $35 \%$ PUFA and approximately $20 \%$ SFA. Moreover, virgin argan oil contains minor, bioactive components such as phenolic compounds, phytosterols and tocopherols ${ }^{(11,12)}$.

Despite suggestive in vitro and animal evidence, the potential cardioprotective properties of argan oil have been the subject of very limited studies in humans ${ }^{(8,13)}$. Moreover, the in vivo effects of Algerian argan oil have never been investigated. Therefore, we sought to comprehensively determine the effects of argan oil supplementation on plasma lipid profile and antioxidant status of a group of healthy Algerian subjects, compared with matched controls.

\section{Experimental methods}

\section{Materials and methods}

Argan fruits were harvested in the Tindouf area of Southwestern Algeria. The argan oil used in the present work was

Abbreviations: CAT, catalase; LOOH, lipoperoxides; ORAC, oxygen radical absorbance capacity; TBARS, thiobarbituric acid-reacting substances. 
Table 1. Composition of the argan oil adopted in this study

\begin{tabular}{lc}
\hline Fatty acid & $\%$ \\
\hline C16: $: 0$ & $12 \cdot 89$ \\
C18:0 & $4 \cdot 83$ \\
C16: $1 n-9$ & $0 \cdot 4$ \\
C18: $1 n-9$ & $45 \cdot 01$ \\
C18: $2 n-6$ & $35 \cdot 39$ \\
C18: $3 n-3$ & $0 \cdot 2$ \\
Total SFA & $17 \cdot 72$ \\
Total MUFA + PUFA & 81 \\
MUFA/PUFA & $1 \cdot 27$ \\
$\alpha$-Tocopherol (mg/kg) & $56 \cdot 34$ \\
Phenolic compounds (mg/kg) & $52 \cdot 36$ \\
\hline
\end{tabular}

produced from freshly picked seeds of a single harvest, using traditional hand-methods. The oil was kept at $4{ }^{\circ} \mathrm{C}$ in a brown glass bottle until the beginning of the trial.

The fatty acid composition of the oil was determined by gasphase chromatography (Applied Sciences Labs, State College, PA, USA). Fatty acid standards were from Nu-Check-Prep (Elysian, MN, USA). Vitamin E ( $\alpha$-tocopherol) was measured by HPLC according to Zaman et al. ${ }^{(14)}$. Polyphenols were extracted from the oil and quantified using the method of Pirisi et al. ${ }^{(15)}$. The composition of the oil at study is given in Table 1 . More than $80 \%$ of total fatty acids was composed of oleic and linoleic acids (45.01 and 35.39\%, respectively). Linolenic acid accounted for only $0.2 \%$ of total fatty acids. SFA (mostly palmitic and stearic acids) accounted for $17 \cdot 7 \%$ of total fatty acids. This oil was devoid of erucic acid. Vitamin $\mathrm{E}$ ( $\alpha$-tocopherol) concentration was quite low, i.e. $56 \cdot 34 \mathrm{mg} / \mathrm{kg}$. Polyphenols were also scarcely present, i.e. $52 \cdot 36 \mathrm{mg} / \mathrm{kg}$.

\section{Subjects}

The present study conforms to the Declaration of Helsinki (Ethical Principles for Medical Research Involving Human Subjects) and was approved by the local ethics committee. A total of forty healthy subjects aged 25-45 years with normal BMI and blood pressure were recruited from within the Abu Bakr Belkaid University (Tlemcen, Algeria) and written or oral informed consent to the study was taken from them. All participants were free of metabolic diseases such as hypercholesterolaemia, hypertriacylglycerolaemia, diabetes and hypertension, and were non-smokers and medication-free. We monitored the volunteers' lifestyle, e.g. physical activity, working hours and sleep duration, which did not markedly change throughout this study. A total of twenty subjects consumed $15 \mathrm{~g} / \mathrm{d}$ of argan oil - with toasted bread - for breakfast, during 4 weeks (intervention group), whereas twenty matched controls followed their habitual diet, but did not consume argan oil. We found that provision of argan oil translated into lower consumption of habitual fat (oils and, to a lower extent, butter). It is noteworthy that, unexpectedly, consumption of olive oil in Algeria is quite low (approximately $1 \mathrm{~kg}$ / year), whereas milk consumption is higher than in neighbouring Maghreb countries ${ }^{(16,17)}$.

We chose the dose of $15 \mathrm{~g} / \mathrm{d}$ because (a) it was well tolerated by our volunteers and approximates habitual consumption and (b) Drissi et al. ${ }^{(8)}$ previously reported on the healthful effects of this daily dose.

Both groups had similar anthropometric characteristics (Table 2). All subjects filled in a food questionnaire, in which they noted the quality and quantity of food consumed during the day before blood sampling, including their argan oil intake (which was nil in controls). The registered values were converted into energy and were estimated according to the Ciqual standard table of food composition ${ }^{(18)}$. All participants had similar physical activity and lifestyle.

\section{Blood analyses}

At days $0\left(T_{0}\right), 15\left(T_{15}\right)$ and $30\left(T_{30}\right)$, venous blood was drawn into evacuated tubes, some of which contained disodium EDTA as the anticoagulant; other tubes did not contain anticoagulants to allow for the preparation of serum. Both serum and plasma were separated by centrifugation at $2100 \mathrm{~g}$ for $20 \mathrm{~min}$ at $4{ }^{\circ} \mathrm{C}$, aliquoted, and stored at $-20^{\circ} \mathrm{C}$. Erythrocytes were collected and washed three times in isotonic saline; then they were haemolysed by the addition of cold distilled water $(1 / 4, \mathrm{vol} / \mathrm{vol})$. Cellular debris was removed by centrifugation.

\section{Lipoprotein and lipid determination}

Plasma lipoproteins (LDL, $d<1.063$; HDL, $d<1.21 \mathrm{~g} / \mathrm{ml}$ ) were separated by sequential ultracentrifugation. Serum total cholesterol (TC) and TAG were measured using enzymatic kits (Quimica Clinica Aplicada S.A., Amposta, Spain). HDL-cholesterol and LDL-cholesterol concentrations were also measured by enzymatic kits.

\section{Determination of hydroperoxides}

Both plasma and erythrocyte levels of hydroperoxides (lipoperoxides, LOOH) were measured by the ferrous ion oxidation-xylenol orange assay - using the specific LOOH reducer triphenylphosphine - according to the method of Nourooz-Zadeh et al. ${ }^{(19)}$.

\section{Determination of thiobarbituric acid-reacting substances}

Thiobarbituric acid-reacting substances (TBARS) in plasma and erythrocytes were measured according to the method of Nourooz-Zadeh et al. ${ }^{(19)}$.

Table 2. Anthropometric characteristics of the study subjects (Mean values and standard deviations)

\begin{tabular}{|c|c|c|c|c|}
\hline & \multicolumn{2}{|c|}{ Argan oil (n 20) } & \multicolumn{2}{|c|}{ Controls (n 20) } \\
\hline & Mean & SD & Mean & SD \\
\hline Age (years) & 37.9 & $2 \cdot 18$ & $35 \cdot 2$ & 1.52 \\
\hline $\mathrm{BMI}\left(\mathrm{kg} / \mathrm{m}^{2}\right)$ & 23.08 & 0.37 & $22 \cdot 82$ & 0.55 \\
\hline Glycaemia (mg/l) & 931 & $20 \cdot 0$ & 926 & $18 \cdot 7$ \\
\hline $\mathrm{SBP}(\mathrm{mmHg})$ & 117 & 2.59 & 115.5 & $2 \cdot 32$ \\
\hline DBP $(\mathrm{mmHg})$ & 73.5 & 1.29 & $70 \cdot 5$ & $1 \cdot 7$ \\
\hline
\end{tabular}

SBP, systolic blood pressure; DBP, diastolic blood pressure. 
Table 3. Dietary intakes at day 30

\begin{tabular}{|c|c|c|c|c|c|c|c|c|}
\hline & \multicolumn{4}{|c|}{ Argan oil ( $n$ 20) } & \multicolumn{4}{|c|}{ Controls ( $n 20)$} \\
\hline & \multicolumn{2}{|c|}{$g / d$} & \multicolumn{2}{|c|}{$\%$} & \multicolumn{2}{|c|}{$g / d$} & \multicolumn{2}{|c|}{$\%$} \\
\hline & Mean & SD & Mean & SD & Mean & SD & Mean & SD \\
\hline \multicolumn{9}{|l|}{ Energy intake } \\
\hline $\mathrm{kcal} / \mathrm{d}$ & 2108.06 & & $40 \cdot 59$ & & $2100 \cdot 14$ & & $93 \cdot 28$ & \\
\hline $\mathrm{kJ} / \mathrm{d}$ & $8820 \cdot 12$ & & $169 \cdot 82$ & & 8786.98 & & $390 \cdot 28$ & \\
\hline Total protein & 74.86 & $2 \cdot 86$ & $14 \cdot 20$ & 0.55 & 73.83 & 3.89 & 14.06 & 0.78 \\
\hline Total sugars & $313 \cdot 24$ & $9 \cdot 70$ & $59 \cdot 43$ & $1 \cdot 87$ & 319.58 & 7.46 & $60 \cdot 86$ & 1.95 \\
\hline Simple sugars & $100 \cdot 85$ & $2 \cdot 64$ & $32 \cdot 19$ & 1.42 & 104.05 & $4 \cdot 84$ & 32.55 & 1.75 \\
\hline Complex sugars & $212 \cdot 39$ & 9.98 & $67 \cdot 80$ & 3.46 & 215.53 & $7 \cdot 69$ & $67 \cdot 44$ & 2.78 \\
\hline Total lipids & $61 \cdot 74$ & 3.82 & $26 \cdot 35$ & 1.66 & 58.5 & $2 \cdot 79$ & $25 \cdot 06$ & 1.26 \\
\hline SFA & $22 \cdot 41$ & 1.23 & $36 \cdot 92$ & $2 \cdot 31$ & 23.02 & $1 \cdot 28$ & 39.35 & $2 \cdot 66$ \\
\hline MUFA & $20 \cdot 75$ & 1.74 & 33.60 & 3.26 & $20 \cdot 78$ & $1 \cdot 17$ & $35 \cdot 52$ & 2.43 \\
\hline PUFA & $18 \cdot 58^{\star}$ & $1 \cdot 17$ & $30 \cdot 09^{*}$ & $2 \cdot 19$ & 14.7 & 0.96 & $25 \cdot 12$ & 2.00 \\
\hline Cholesterol (mg/d) & \multicolumn{2}{|c|}{244.82} & \multicolumn{2}{|c|}{15.58} & \multicolumn{2}{|c|}{$257 \cdot 72$} & \multicolumn{2}{|c|}{34.74} \\
\hline
\end{tabular}

${ }^{*}$ Mean values were significantly different $(P<0.05)$

\section{Determination of carbonyl proteins}

Carbonyl proteins were measured in plasma and erythrocytes by the 2,4-dinitrophenylhydrazine reaction described by Levine et $a l .{ }^{(20)}$.

\section{Conjugated diene formation}

The in vitro oxidisability of plasma lipoproteins induced by metals, i.e. copper sulphate, was analysed by monitoring, over time, the formation of conjugated dienes, as described by Esterbauer et $a l^{(21)}$

\section{Determination of plasma levels of vitamins $A, E$ and $C$}

Vitamins A (retinol) and E ( $\alpha$-tocopherol) were determined in the plasma of all volunteers by HPLC coupled with UV detection at $292 \mathrm{~nm}$ for vitamin $\mathrm{E}$ and $325 \mathrm{~nm}$ for vitamin A, according to Zaman et al. ${ }^{(14)}$. Vitamin $\mathrm{C}$ was measured in plasma by the method of Jagota \& Dani ${ }^{(22)}$.

\section{Determination of catalase activity}

Catalase (CAT; EC 1.11.1.6) activity was measured by spectrophotometric analysis of the rate of $\mathrm{H}_{2} \mathrm{O}_{2}$ decomposition at $240 \mathrm{~nm}$, according to the method of $\mathrm{Aebi}^{(23)}$.

\section{Oxygen radical absorbance capacity}

The total antioxidant ability of plasma (oxygen radical absorbance capacity, ORAC) was estimated by the capacity of erythrocytes to resist free-radical-induced haemolysis, according to the method of Blache \& Prost ${ }^{(24)}$.

\section{Statistical analysis}

Results are expressed as means and standard deviations. The Student's $t$ test was used to compare data from the intervention group with those from controls. Statistical analysis was performed using Statistica (version 4.1, Statsoft, Paris, France). A $P$ value less than 0.05 was considered as statistically significant.

\section{Results}

\section{Dietary profile}

Neither total daily energy intake nor consumption of proteins, carbohydrates and lipids significantly differed between the two groups during the experiment (Table 3). Consumption of SFA and MUFA was also similar in both groups; however, argan oil intake resulted in a higher overall consumption of PUFA (Table 3).

Table 4. Plasma lipid profile of argan oil-supplemented (A) and control (C) subjects, at different time points†

(Mean values and standard deviations)

\begin{tabular}{|c|c|c|c|c|c|c|c|c|}
\hline & \multicolumn{2}{|c|}{ C } & \multicolumn{2}{|c|}{$\mathrm{A}-T_{0}$} & \multicolumn{2}{|c|}{ A- $T_{15}$} & \multicolumn{2}{|c|}{$\mathrm{A}-T_{30}$} \\
\hline & Mean & SD & Mean & SD & Mean & SD & Mean & SD \\
\hline TAG (mg/l) & 1210 & 80 & 1240 & 10 & 1170 & 90 & $980^{*}$ & 60 \\
\hline $\mathrm{TC}(\mathrm{mg} / \mathrm{l})$ & 1620 & 70 & 1640 & 60 & 1520 & 40 & $1400^{*}$ & 60 \\
\hline HDL-C (mg/l) & 420 & 20 & 410 & 20 & 440 & 20 & 470 & 10 \\
\hline LDL-C (mg/l) & 790 & 30 & 810 & 30 & 730 & 20 & $680^{\star *}$ & 20 \\
\hline
\end{tabular}

$T_{0}$, day $0 ; T_{15}$, day $15 ; T_{30}$, day 30 ; TC, total cholesterol; HDL-C, HDL-cholesterol; LDL-C, LDLcholesterol.

Mean values were significantly different from those of controls: ${ }^{\star} P<0.05,{ }^{\star \star} P<0.001$

$\dagger$ The plasma lipid profile of control subjects did not change significantly throughout the study: we present the average value of $T_{0}+T_{15}+T_{30}$. 
Table 5. Circulating and cellular markers of lipid and protein oxidation of argan oil-supplemented (A) and control (C) subjects, at different time points $\dagger$

(Mean values and standard deviations)

\begin{tabular}{|c|c|c|c|c|c|c|c|c|}
\hline & \multicolumn{2}{|c|}{ C } & \multicolumn{2}{|c|}{$\mathrm{A}-T_{0}$} & \multicolumn{2}{|c|}{ A- $T_{15}$} & \multicolumn{2}{|c|}{$\mathrm{A}-T_{30}$} \\
\hline & Mean & SD & Mean & SD & Mean & SD & Mean & SD \\
\hline TBARS pl $(\mu \mathrm{mol} / \mathrm{l})$ & 1.31 & 0.05 & 1.45 & 0.06 & 1.31 & 0.08 & $1.19^{*}$ & 0.06 \\
\hline TBARS erythrocytes $(\mu \mathrm{mol} / \mathrm{l})$ & 8.67 & 1.57 & $8 \cdot 70$ & 1.71 & 7.89 & 1.30 & $6 \cdot 65^{\star}$ & 1.51 \\
\hline $\mathrm{LOOH} \mathrm{pl}(\mu \mathrm{mol} / \mathrm{l})$ & 0.86 & 0.11 & 0.93 & 0.13 & 0.77 & 0.11 & $0.46^{\star \star}$ & 0.05 \\
\hline $\mathrm{LOOH}$ erythrocytes $(\mu \mathrm{mol} / \mathrm{l})$ & 9.98 & 1.40 & $10 \cdot 3$ & 1.33 & 9.42 & 1.37 & $8.09^{*}$ & 1.30 \\
\hline $\mathrm{PC} \mathrm{pl}(\mathrm{nmol} / \mathrm{l})$ & 61.55 & 2.35 & $62 \cdot 74$ & 2.48 & $59 \cdot 47$ & $2 \cdot 39$ & $56 \cdot 83^{*}$ & 2.03 \\
\hline PC erythrocytes $(\mathrm{nmol} / \mathrm{l})$ & 90.97 & $5 \cdot 18$ & 94.93 & $6 \cdot 31$ & 87.85 & 5.02 & 81.05 & 4.83 \\
\hline
\end{tabular}

$T_{0}$, day $0 ; T_{15}$, day $15 ; T_{30}$, day 30 ; TBARS, thiobarbituric acid-reacting substances; pl, plasma; LOOH, lipoperoxides; PC, protein carbonyls.

Mean values were significanty different from those of controls: ${ }^{*} P<0.05,{ }^{* *} P<0.01$.

$\dagger$ The biomarkers of control subjects did not change significantly throughout the study: we present the average value of $T_{0}+T_{15}+T_{30}$.

\section{Circulating lipids}

We recorded a significant improvement in the plasma lipid profile of subjects who were given argan oil as compared to controls, whose values did not significantly change during the study (data not shown). In particular, TAG decreased by $20.97 \%$, TC by $14.63 \%$ and LDL-cholesterol by $16.05 \%$ after $30 \mathrm{~d}$ of treatment (Table 4). We also recorded a concomitant non-significant increase in HDL-cholesterol.

\section{Circulating and cellular markers of oxidation and antioxidant status}

Circulating and cellular markers of lipid (TBARS and LOOH) and protein (carbonyls) oxidation are shown in Table 5. Argan oil significantly decreased the former (at $T_{30}$ ), but not the latter. In addition, susceptibility of LDL to copper-induced oxidation was decreased in argan oil-treated subjects, as indicated by the significantly increased lag phase and decrease of conjugated diene production (Table 6).

Plasma vitamin E concentrations were significantly increased $\left(+18 \%\right.$ at $T_{15}, P<0.05$ and $+43 \%$ at $T_{30}, P<0.001$ when compared with controls; Table 7) by argan oil ingestion throughout the study. Conversely, vitamins A and $\mathrm{C}$ did not change significantly in either group. CAT activity also increased significantly in argan oil-treated subjects, whereas plasma ORAC remained unmodified.

\section{Discussion}

We performed the first trial of Algerian argan oil in human subjects and evaluated a wide array of surrogate markers of CVD. Our present study results show that daily consumption of feasible amounts of argan oil positively modulates such markers. Argan oil consumption is increasing in Europe and high-quality virgin argan oil can also be currently purchased in Japan and the USA, where it is mostly sold for its purported cosmetic properties. Thus far, due to its elevated price, the dietary use of argan oil is mostly limited to the areas where it is produced (for the most part Morocco, although West Algeria also contributes). As such, it contributes to the diet of selected population groups and is an integral part of the Maghrebian version of the Mediterranean diet.

Our results are in agreement with those of Drissi et al ${ }^{(8)}$ and of Cherki et al. ${ }^{(13)}$ and fit with cumulated animal evidence of the anti-atherogenic potential of argan oil ${ }^{(7)}$. In particular, argan oil consumption - in feasible amounts - decreased total and LDL-cholesterol and TAG. Of note, our subjects had low mean cholesterolaemia, which reflects the average values found in countryside Algeria. Other cardiovascular parameters such as blood pressure were not modified by argan oil consumption, in contrast with the findings of Berrougui et $a{ }^{(25)}$ who reported hypotensive effects in normotensive Wistar rats. This discrepancy might be due to species specificity, dose or treatment duration.

Table 6. Susceptibility of LDL to oxidation of argan oil-supplemented (A) and control (C) subjects, at different time points $†$

(Mean values and standard deviations)

\begin{tabular}{|c|c|c|c|c|c|c|c|c|}
\hline & \multicolumn{2}{|c|}{ C } & \multicolumn{2}{|c|}{$\mathrm{A}-T_{0}$} & \multicolumn{2}{|c|}{ A $-T_{15}$} & \multicolumn{2}{|c|}{$\mathrm{A}-T_{30}$} \\
\hline & Mean & SD & Mean & SD & Mean & SD & Mean & SD \\
\hline LP (min) & 57.5 & 5.40 & $56 \cdot 25$ & 4.78 & $62 \cdot 75$ & 5.75 & $67 \cdot 5^{\star}$ & 6.45 \\
\hline MR (min) & $122 \cdot 5$ & $6 \cdot 45$ & $123 \cdot 25$ & 7.05 & 124.55 & $7 \cdot 27$ & $126 \cdot 75$ & $8 \cdot 16$ \\
\hline IDP (nmol/l) & 33.05 & 1.39 & $36 \cdot 68$ & 0.62 & $32 \cdot 22$ & 0.58 & $30 \cdot 83$ & 0.95 \\
\hline MDP (nmol/l) & $40 \cdot 83$ & $4 \cdot 61$ & $43 \cdot 25$ & 4.97 & $38 \cdot 30$ & 4.53 & $33 \cdot 7^{\star}$ & 3.94 \\
\hline
\end{tabular}

$T_{0}$, day $0 ; T_{15}$, day $15 ; T_{30}$, day 30 ; LP, lag phase; MR, maximal rate; IDP, initial conjugated diene production; MDP, maximum conjugated diene production.

${ }^{*}$ Mean values were significantly different from those of controls $(P<0.05)$.

$\dagger$ The susceptibility of LDL to oxidation of control subjects did not change significantly throughout the study: we present the average value of $T_{0}+T_{15}+T_{30}$. 
Table 7. Plasma antioxidant parameters of argan oil-supplemented (A) and control (C) subjects, at different time points

(Mean values and standard deviations)

\begin{tabular}{|c|c|c|c|c|c|c|c|c|}
\hline & \multicolumn{2}{|c|}{ C } & \multicolumn{2}{|c|}{$\mathrm{A}-T_{0}$} & \multicolumn{2}{|c|}{ A $-T_{15}$} & \multicolumn{2}{|c|}{$\mathrm{A}-T_{30}$} \\
\hline & Mean & SD & Mean & SD & Mean & SD & Mean & SD \\
\hline Vitamin $C(\mu \mathrm{g} / \mathrm{ml})$ & $13 \cdot 25$ & 0.31 & 13.42 & 0.43 & 13.05 & 0.25 & $13 \cdot 6$ & 0.46 \\
\hline Vitamin $E(\mu \mathrm{g} / \mathrm{ml})$ & 21.52 & 1.78 & 21.46 & 1.75 & $25 \cdot 21^{*}$ & 1.92 & $30 \cdot 66^{* *}$ & $2 \cdot 01$ \\
\hline Vitamin A $(\mu \mathrm{g} / \mathrm{ml})$ & $66 \cdot 54$ & 1.59 & 66.92 & 1.91 & 65.46 & 0.68 & 71.54 & 1.98 \\
\hline ORAC (AU) & $2 \cdot 22$ & 0.11 & $2 \cdot 1$ & $0 \cdot 10$ & 2.43 & 0.11 & $2 \cdot 97$ & 0.12 \\
\hline CAT pl (U/ml) & 0.23 & 0.02 & 0.22 & 0.02 & 0.26 & 0.03 & 0.28 & 0.03 \\
\hline CAT erythrocytes (U/ml) & $81 \cdot 21$ & $2 \cdot 64$ & $80 \cdot 12$ & 1.95 & 82.05 & 1.71 & $88 \cdot 88^{*}$ & $2 \cdot 08$ \\
\hline
\end{tabular}

$T_{0}$, day $0 ; T_{15}$, day $15 ; T_{30}$, day 30; ORAC, oxygen radical absorbance capacity; AU, arbitrary; CAT, catalase; pl, plasma. Mean values were significantly different from those of controls: ${ }^{\star} P<0.05,{ }^{\star \star} P<0.01$.

The exact mechanisms of action by which argan oil exerts its lipid-modulating and potentially anti-atherogenic actions remain elusive. However, we speculate that the high proportion of PUFA and MUFA in the argan oil we administered - and reflected in the overall dietary intake (Table 3) - played marked roles, as suggested by the available literature ${ }^{(26,27)}$. Other contributors to the hypolipidaemic effects of argan oil are - probably - sterols and saponins, which we did not measure in the present investigation due to technical limitations, but which have been previously investigated by Khallouki et $a l^{(11)}$ and Berrougui et al. ${ }^{(28)}$. Both classes of molecules interfere with intestinal cholesterol absorption and are currently exploited as functional food components ${ }^{(29)}$

We also evaluated circulating markers of oxidation and report that argan oil consumers had lower concentrations of LOOH and TBARS, but not of oxidatively-modified proteins. Total antioxidant capacity (evaluated as ORAC) also did not change. Finally, we recorded increased intracellular CAT activity. This finding is, indeed, counterintuitive (there should be no reason to activate an antioxidant enzyme if the antioxidant profile is augmented). However, several studies with antioxidants, e. g. polyphenols, reported similar increases in the activity of antioxidant enzymes, namely superoxide dismutase and CAT ${ }^{(30)}$. As far as argan oil is concerned, our results agreed with those of Benajiba et $a l .^{(31)}$, which showed that the activities of cytosolic CAT were significantly higher in Wistar rats treated with argan oil in comparison with the untreated rats. We can conceivably attribute the observed antioxidant actions (including increased LDL resistance to oxidation, which confirms previous findings of Cherki et $a l .{ }^{(13)}$ ) to the provision of vitamin $\mathrm{E}$ (which increased in consumers' plasma, Table 7) by argan oil. While Algerian argan oil appears to contain less vitamin E than, for example, the average Moroccan argan oil or extra-virgin olive oil, the contribution of tocopherols to the overall intake is, apparently, sufficient to elicit antioxidant effects. Other components such as polyphenols, namely ferulic acid (32), and sterols might have played a role. The precise nature of the cumulative positive effects on antioxidant profile, however, is still elusive and requires ad hoc investigations.

Our present study has several limitations - most of which are due to technical constraints - which we should acknowledge. As mentioned, we could not analyse the argan oil's content of sterols and saponins and, thus, we rely on the data of Khallouki et al. ${ }^{(11)}$ and Berrougui et al. ${ }^{(28)}$. We also could not evaluate the modifications of plasma and lipoprotein lipid profile brought about by consumption of argan oil. Hence, we rely on food composition tables to estimate intakes. Finally, we assessed an array of lipid peroxidation indices, due to the current lack of robust biomarkers $^{(33)}$; however, each of them has shortcomings ${ }^{(34)}$.

In conclusion, we showed that argan oil is able to positively modulate some surrogate markers of CVD, through mechanisms which warrant further investigation. Moreover, based on these results, argan oil could prove to be an effective livelihood opportunity to diversify the options of small rural Berber producers and enhance their incomes.

\section{Acknowledgements}

We thank all the volunteers for their cooperation. We also thank the UPRES Laboratory of Lipids and Nutrition, Faculty of Sciences Gabriel, Burgundy University (Dijon, France). All authors read and approved the manuscript. S. S., D. K., N. B., N. S. and A. N. recruited the volunteers, analysed the FFQ and performed the biochemical analyses. M. B., F. C. and F. V. supervised the study and wrote the paper. All authors declare that there are no conflicts of interest. The present research received no specific grant from any funding agency in the public, commercial or not-for-profit sectors.

\section{References}

1. McNaughton SA, Mishra GD \& Brunner EJ (2009) Food patterns associated with blood lipids are predictive of coronary heart disease: the Whitehall II study. Br J Nutr 102, 619-624.

2. Martinez-Gonzalez MA, Bes-Rastrollo M, Serra-Majem L, et al. (2009) Mediterranean food pattern and the primary prevention of chronic disease: recent developments. Nutr Rev 67, Suppl. 1, S111-S116.

3. Bedard A, Goulet J, Riverin M, et al. (2010) Effects of a dietary intervention promoting the adoption of a Mediterranean food pattern on fast-food consumption among healthy French-Canadian women. Br J Nutr 104, 1662-1665.

4. Bogani P \& Visioli F (2007) Antioxidants in the Mediterranean diets: an update. World Rev Nutr Diet 97, 162-179.

5. Bere E \& Brug J (2010) Is the term 'Mediterranean diet' a misnomer? Public Health Nutr 13, 2127-2129. 
6. Visioli F \& Bernardini E (2011) Extra Virgin Olive Oil's Polyphenols: biological activities. Curr Pharm Des 17, 786-804.

7. Charrouf Z \& Guillaume D (2010) Should the amazigh diet (regular and moderate argan-oil consumption) have a beneficial impact on human health? Crit Rev Food Sci Nutr 50, 473-477.

8. Drissi A, Girona J, Cherki M, et al. (2004) Evidence of hypolipemiant and antioxidant properties of argan oil derived from the argan tree (Argania spinosa). Clin Nutr 23, $1159-1166$

9. Bennani H, Drissi A, Giton F, et al. (2007) Antiproliferative effect of polyphenols and sterols of virgin argan oil on human prostate cancer cell lines. Cancer Detect Prev 31, 64-69.

10. Berrougui H, Ettaib A, Herrera G, et al. (2003) Hypolipidemic and hypocholesterolemic effect of argan oil (Argania spinosa L.) in Meriones shawi rats. J Ethnopharmacol 89, $15-18$.

11. Khallouki F, Younos C, Soulimani R, et al. (2003) Consumption of argan oil (Morocco) with its unique profile of fatty acids, tocopherols, squalene, sterols and phenolic compounds should confer valuable cancer chemopreventive effects. Eur J Cancer Prev 12, 67-75.

12. Cherki M, Berrougui H, Drissi A, et al. (2006) Argan oil: which benefits on cardiovascular diseases? Pharmacol Res 54, 1-5.

13. Cherki M, Derouiche A, Drissi A, et al. (2005) Consumption of argan oil may have an antiatherogenic effect by improving paraoxonase activities and antioxidant status: intervention study in healthy men. Nutr Metab Cardiovasc Dis 15, $352-360$.

14. Zaman Z, Fielden P \& Frost PG (1993) Simultaneous determination of vitamins $\mathrm{A}$ and $\mathrm{E}$ and carotenoids in plasma by reversed-phase HPLC in elderly and younger subjects. Clin Chem 39, 2229-2234

15. Pirisi FM, Cabras P, Cao CF, et al. (2000) Phenolic compounds in virgin olive oil. 2. Reappraisal of the extraction, HPLC separation, and quantification procedures. J Agric Food Chem 48, 1191-1196.

16. Kallithraka S, el-Jazouli A \& Zeghichi S (2000) Mediterranean diets in the Maghreb. World Rev Nutr Diet 87, 160-179.

17. Zeghichi-Hamri S \& Kallithraka S (2007) Mediterranean diet in the Maghreb: an update. World Rev Nutr Diet 97, 139-161.

18. Anonymous (1991) Répertoire général des aliments: technique et documentation (General list of foods: technical documentation). Paris: Lavoisier-INRA-Ciqual-Régal Edit.

19. Nourooz-Zadeh J, Tajaddini-Sarmadi J, Ling KL, et al. (1996) Low-density lipoprotein is the major carrier of lipid hydroperoxides in plasma. Relevance to determination of total plasma lipid hydroperoxide concentrations. Biochem J $\mathbf{3 1 3}$, $781-786$.
20. Levine RL, Garland D, Oliver CN, et al. (1990) Determination of carbonyl content in oxidatively modified proteins. Methods Enzymol 186, 464-478.

21. Esterbauer H, Striegl G, Puhl H, et al. (1989) Continuous monitoring of in vitro oxidation of human low density lipoprotein. Free Radic Res Commun 6, 67-75.

22. Jagota SK \& Dani HM (1982) A new colorimetric technique for the estimation of vitamin $\mathrm{C}$ using Folin phenol reagent Anal Biochem 127, 178-182.

23. Aebi H (1974) Catalase. In Methods of Enzymatic Analysis, 2nd ed., pp. 673-684 [HU Bergmeyer, editor]. Veinheim: Verlag Chemie.

24. Blache D \& Post M (1992) Free radical attack: biological test for human resistance capability. In Proceedings of the College Park on Chemical Evolution, pp. 82-98. Washington, DC: Chemical Analysis Laboratory.

25. Berrougui H, Alvarez dS, Perez-Guerrero C, et al. (2004) Argan (Argania spinosa) oil lowers blood pressure and improves endothelial dysfunction in spontaneously hypertensive rats. Br J Nutr 92, 921-929.

26. Ramsden CE, Hibbeln JR, Majchrzak SF, et al. (2010) n-6 fatty acid-specific and mixed polyunsaturate dietary interventions have different effects on CHD risk: a meta-analysis of randomised controlled trials. Br J Nutr 104, 1586-1600.

27. Calder PC (2010) The American Heart Association advisory on $n$ - 6 fatty acids: evidence based or biased evidence? $\mathrm{Br}$ Nutr 104, 1575-1576.

28. Berrougui $\mathrm{H}$, Cloutier M, Isabelle $\mathrm{M}$, et al. (2006) Phenolicextract from argan oil (Argania spinosa L.) inhibits human low-density lipoprotein (LDL) oxidation and enhances cholesterol efflux from human THP-1 macrophages. Atherosclerosis 184, 389-396.

29. Marangoni F \& Poli A (2010) Phytosterols and cardiovascular health. Pharmacol Res 61, 193-199.

30. Hassimotto NM, Pinto MS \& Lajolo FM (2008) Antioxidant status in humans after consumption of blackberry (Rubus fruticosus L.) juices with and without defatted milk. J Agric Food Chem 56, 11727-11733.

31. Benajiba N, Morel S, De Leiris J, et al. (2002) The effect of argan oil on heart function during ischemia and reperfusion. Therapie 57, 246-252.

32. Zougagh M, Salghi R, Dhair S, et al. (2011) Nanoparticlebased assay for the detection of virgin argan oil adulteration and its rapid quality evaluation. Anal Bioanal Chem 399, 2395-2405.

33. Spickett CM, Wiswedel I, Siems W, et al. (2010) Advances in methods for the determination of biologically relevant lipid peroxidation products. Free Radic Res 44, 1172-1202.

34. Halliwell B (2000) Lipid peroxidation, antioxidants and cardiovascular disease: how should we move forward? Cardiovasc Res 47, 410-418. 